\title{
Investigation of quality and antimicrobal activity of cultivated marigold flowers Calendula officinalis $L$.
}

\author{
Katarina Gurzulov ${ }^{1}$, Mirjana Marčetić ${ }^{2}$ Dragana Božić3
}

\author{
${ }^{1}$ Farmaceutski fakultet, Univerzitet u Beogradu \\ ${ }^{2}$ Katedra za farmakognoziju, Farmaceutski fakultet, Univerzitet u Beogradu \\ ${ }^{3}$ Katedra za mikrobiologiju i imunologiju, Farmaceutski fakultet, Univerzitet u Beogradu
}

Kontakt: kacagurzulov@gmail.com

\section{Sažetak}

Uvod: Cvast nevena, Calendula officinalis L., Asteraceae, tradicionalno se koristi za lečenje kožnih bolesti. Cvast nevena sadrži triterpenske saponine, karotenoide, flavonoide i etarsko ulje. Ekstrakti i etarsko ulje cvasti nevena pokazuju antiinflamatornu, antioksidantnu i antimikrobnu aktivnost.

Cilj rada: Cilj rada je bio ispitivanje kvaliteta cvasti gajenog nevena, Calendulae flos, upoređivanje sadržaja flavonoida u cvasti i jezičastim cvetovima, kao i utvrđivanje antimikrobne aktivnosti ekstrakata i tradicionalne masti na bazi nevena.

Materijal i metode: Biljni materijal je prikupljen iz privatnih bašti u Kikindi, Mokrinu i Vrnjačkoj Banji tokom septembra i novembra 2015. godine. Ispitivanje kvaliteta je obuhvatalo makroskopsku i mikroskopsku analizu i određivanje specifičnog kvaliteta prema monografiji Evropske farmakopeje 7.0. Identifikacija flavonoida je izvršena metodom tečne hromatografije pod visokim pritiskom (HPLC). Antimikrobna aktivnost etanolnih ekstrakata (1:20) i tradicionalnih masti na bazi jezičastih cvetova ili celih cvasti ispitivana je na šest standardnih laboratorijskih sojeva agar-difuzionim matodom.

Rezultati: Makroskopske i mikroskopske karakteristike i sadržaj flavonoida $(2,0-2,76 \%)$ u jezičastim cvetovima gajenog nevena odgovarali su zahtevima propisanom u Ph.Eur. 7.0. Izdvojeni jezičasti cvetovi $(2,76 \pm 0,01 \%)$ sadržali su veću koncentraciju flavonoida od celih cvasti $(1,68 \pm 0,0 \%)$. U jezičastim cvetovima su uočene i razlike u sadržaju flavonoida tokom septembra $(2,76 \pm 0,01 \%)$ i novembra $(1,45 \pm 0,01 \%)$, dok se u celim cvetovima koncentracija nije značajno menjala. U svim ispitivanim uzorcima identifikovani su 3-O-heterozidi kvarcetina i izoramnetina. Antimikrobno delovanje su pokazali etanolni ekstrakti jezičastih i celih cvetova, kao i tradicionalne masti. Tradicionalna mast na bazi jezičastih cvetova pokazala je izraženiji antimikrobni efekat od masti na bazi celih cvasti.

Zaključak: Ispitivanje kvaliteta je pokazalo da cvast gajenog nevena odgovara zahtevima Ph.Eur.7.0. Jezičasti cvetovi su sadržali više flavonoida od celih cvasti nevena. Ekstrakti i tradicionalna mast na bazi jezičastih cvetova pokazali su antimikrobnu aktivnost, što potvrđuje dugogodišnju upotrebu nevena.

Ključne reči: cvast nevena, Calendula officinalis, flavonoidi, antimikrobna aktivnost

\begin{abstract}
Introduction: Marigold flower, Calendula officinalis $L$, Asteraceae, is traditionally used to treat skin diseases. Marigold flowers contain triterpenoid saponins, carotenoids, flavonoids and essential oil. Extracts and essential oil exhibit anti-inflammatory, antioxidant and antimicrobial activity.

Aim: The aim of the study was to investigate quality of cultivated Calendulae flos, to compare flavonoids content in inflorescence and ligulate florets and to determine antimicrobial activity of extract and traditional ointment based on marigold.

Material and Methods: Plant material was collected from private gardens in Kikinda, Mokrin and Vrnjacka Banja during September and November 2015. Quality investigation included: macroscopic and microscopic analysis and determination of the specific quality according to the monograph of European Pharmacopoeia 7.0. The identification of flavonoids was carried out by HPLC. Antimicrobial activity of ethanol extracts (1:20) and traditional ointment based on ligulate florets or whole inflorescences was tested against six standard laboratory strains by agar-diffusion method.
\end{abstract}

Results: Macroscopic and microscopic characteristics and content of flavonoids (2.0-2.76\%) in the ligulate florets of cultivated marigold corresponded to the requirements of $P h$. Eur. 7.0. Separated ligulate florets $(2.76 \pm 0.01 \%)$ contained a higher concentration of flavonoids than whole inflorescence $(1.68 \pm 0.0 \%)$. Also, in ligulate florets differences were found in the flavonoids content during September ( 2.76 $\pm 0.01 \%)$ and November $(1.45 \pm 0.01 \%)$, while in whole inflorescences concentration didn't significantly change. In all tested samples 3-O-heterosides of quercetin and isorhamnetin were identified. The ethanol extracts of ligulate florets, whole inflorescence as well as traditional ointments showed the antimicrobial activity. The traditional ointment based on ligulate florets showed stronger antimicrobial effect than the ointment based on full inflorescences.

Conclusion: Quality investigation showed that cultivated marigold flowers meet the requirements of Ph. Eur. 7.0. Ligulate florets contained more flavonoids than whole inflorescences. Extracts and traditional ointment based on ligulate florets showed antimicrobial activity, which confirmed long-term use of marigold.

Key words: marigold flowers, Calendula officinalis, flavonoids, antimicrobial activity 


\section{Uvod}

Današnja farmacija i medicina pored velikog broja sintetičkih lekova, sve više pažnje poklanjaju prirodnim izvorima lekovitih supstanci, na prvom mestu lekovitim biljkama. Neven je široko korišćena lekovita biljka u farmaceutskim proizvodima, kozmetici, parfemima i ishrani (1).

Rod Calendula L. obuhvata 15-20 vrsta, koje se javljaju u mediteranskoj oblasti i na Kanarskim ostrvima. U Flori Srbije su opisane dve vrste: Calendula officinalis L. i C. arvensis (Vaill.) L.

Neven, Calendula officinalis, jednogodišnja je zeljasta, ređe višegodišnja biljka, visoka $30-50 \mathrm{~cm}$ sa dugačkim vretenastim korenom. Stabljika je uglasta i kratko maljava, a listovi živozeleni, uglavnom sa celim obodom. U donjem delu stabljike listovi su lopatičasti, dugački i suženi u obliku drške, dok su u gornjem delu stabljike sedeći, duguljasto lancetasti do jajasti. Cvetne glavice su velike 2-5 $\mathrm{cm}$ u prečniku, u vreme cvetanja krute i uspravne. Listići involukruma su lancetasti sa trepljastim dlakama. Cvasti su žute ili narandžaste, pojedinačne i svojstvenog mirisa. Središnji cvetovi su dvopolni, cevasti i neplodni. Obodni cvetovi su u 1-3 reda, mnogobrojni ženski i plodni. Vrsta C. officinalis je verovatno poreklom sa Mediterana, a gaji se po baštama i parkovima (2).

Cvasti nevena sadrže karotenoide (flavoksantin, lutein, rubiksantin, $\beta$-karoten, $\gamma$-karoten i likopen), triterpenske saponine (derivate oleanolne kiseline i glukuronske kiseline), triterpenske alkohole, flavonoide (izoramnetin3-O-rutinozid, izoramnetin-3-O-rutinozilramnozid, izoramnetin-3-O-glukozid, izoramnetin-3-O-diglukozid, izokvercitrin, rutin i kvercetin-3-O-rutinozilramnozid), etarsko ulje, tanine i polisaharide (3-7). 3- O-glucoside.

Cvet i, ređe, nadzemni deo biljke u cvetu (Calendulae flos et herba) tradicionalno su se primenjivali kao blag antiseptik za spoljašnju i unutrašnju primenu. U obliku čaja, tinkture ili masti upotrebljavali su se za lečenje mnogih kožnih bolesti, naročito impetiga (8). Koristili su se kod konjunktivitisa, neredovnih menstruacija, varikoznih vena i hemoroida (9-10).

Ranija ispitivanja su pokazala da etanolni i metanolni ekstrakti cvasti nevena deluju antiinflamatorno, vazoprotektivno, antimikrobno, spazmolitično i antioksidantno, a vodeni ekstrakti ispoljavaju i antiholinesterazni efekat (11-13).

U monografiji Evropske Agencije za lekove navodi se primena tradicionalnih biljnih lekova na bazi cvasti nevena Calendulae flos za simptomatsko lečenje blagih inflamacija kože (poput opekotina od sunca), manjih rana i inflamacija usne duplje. Cvast nevena se primenjuje u vidu infuza, tečnih ekstrakata ili polučvrstih preparata (DER 1:5-1:20) koji se tradicionalno izrađuju od svinjske ili biljne masti (14).
Cilj ovog rada je ispitivanje kvaliteta cvasti gajenog nevena iz privatnih bašti u Kikindi, Mokrinu i Vrnjačkoj Banji, kao i utvrđivanje antimikrobne aktivnosti ekstrakata i tradicionalne masti na bazi nevena.

\section{Materijal i metode}

\section{Biljni materijal}

Cvasti nevena su prikupljene iz privatnih bašti u Kikindi, Mokrinu i Vrnjačkoj Banji tokom septembra 2015. godine i u Kikindi tokom novembra 2015. godine. Drogu predstavljaju cvasti odvojene od čašične lože i sami jezičasti cvetovi sakupljeni u krajnjim fazama cvetanja biljke. Droga je osušena u tankom sloju, na sobnoj temperaturi.

\section{Makroskopska i mikroskopska analiza}

Uzorci jezičastih cvetova iz Kikinde, Mokrina i Vrnjačke Banje (septembar 2015) bili su analizirani organoleptički.

Nakon usitnjavanja droge izvršeno je posmatranje i fotografisanje praška u opštem reaktivu prema Tucakovu pod svetlosnim mikroskopom Olympus BX41.

\section{Izrada etanolnih ekstrakata $i$ tradicionalne masti nevena}

U radu su ispitivani tradicionalno primenjivani etanolni ekstrakti i mast na bazi cvasti nevena, koje kao tradicionalne biljne lekove navodi i Evropska agencija za lekove (14). Suvi jezičasti cretovi $(0,5 \mathrm{~g})$ ili cele crasti nevena $(0,5$ g) ekstrahovani su postupkom maceracije sa po $10 \mathrm{~mL}$ $70 \%$ etanola. Posle 24 časa ekstrakti su filtrirani i korišćeni za dalje ispitivanje.

Tradicionalna mast na bazi nevena izrađena je prema usmenom predanju stanovnika Kikinde. Postupak se zasniva na blagom kuvanju jezičastih cvetova nevena (Kikinda, septembar 2015), ubranih po suvom i sunčanom vremenu između 12 i 14 časova, u domaćoj svinjskoj masti. Zagrevanje je izvršeno u vodenom kupatilu, bez velikog pregrejavanja masti kako bi se sačuvale aktivne komponente cvasti nevena $\left(40-60^{\circ} \mathrm{C}\right)$. Prema tradicionalnom predanju, u rastopljenu mast (130 g) stavljeno je 4 g svežih jezičastih cvetova i mešano 5-10 min (mast 1). Nakon 24 časa stajanja mast je ponovo otopljena i proceđena. Osim tradicionalne masti od svežeg uzorka (Kikinda, novembar 2015) izrađene su još dve masti navedenim postupkom: iz $12 \mathrm{~g}$ svežih jezičastih cvetova nevena i 130 g svinjske masti (mast 2) i iz 12 g svežih celih cvasti nevena i $75 \mathrm{~g}$ svinjske masti (mast 3). 
Određivanje flavonoida u cvasti nevena, Calendulae flos

Određen je sadržaj flavonoida u uzorcima sa različitih lokaliteta (Kikinda, Mokrin i Vrnjačka Banja) i komercijalnom uzorku (Čaj od cveta nevena, Calendulae flos, Institut za proučavanje lekovitog bilja „Dr Josif Pančićc). Ispitivan je i sadržaj flavonoida u celim cvastima (Kikinda) i izdvojenim jezičastim cvetovima, prikupljenih tokom septembra i novembra 2015. godine (Kikinda).

Sadržaj flavonoida u drogi određivan je spektrofotometrijski prema propisu monografije Evropske farmakopeje 7.0 (European Pharmacopoeia 7.0) za Calendulae flos i zasnivalo se na građenju žutih helatnih kompleksa flavonoidnih aglikona sa aluminijum-hloridom (15). Zagrevano je $0,8 \mathrm{~g}$ droge sa $20 \mathrm{~mL}$ acetona, $1 \mathrm{~mL} 5 \mathrm{~g} / \mathrm{L}$ rastvora urotropina i $7 \mathrm{~mL}$ hlorovodonične kiseline. Oslobođeni aglikoni su nakon ceđenja preuzeti etilacetatom. Dodavano je $1,0 \mathrm{~mL}$ reagensa aluminijum-hlorida i izmerena apsorbancija nastalog kompleksa na $425 \mathrm{~nm}$.

\section{Analiza flavonoida pomoću tečne hromatografije pod visokim pritiskom}

Analiza tečnom hromatografijom pod visokim pritiskom (HPLC) izvršena je pomoću aparata Agilent 1100. Korišćena je kolona Zorbax Eclipse XDB-C18 (4,6 x 250 mm, veličine čestica $5 \mu \mathrm{m})$. Identifikacija je vršena pomoću fotodiodnog detektora (engl. photodiode array detector, $D A D)(370 \mathrm{~nm})$. Kao ispitivani uzorci korišćeni su etanolni ekstrakti i etilacetatni ekstrakti flavonoidnih aglikona. Ispitivanje je sprovođeno uz odgovarajući gradijentni protok mobilne faze $\left(0,8 \mathrm{~mL} / \mathrm{min}, 25^{\circ} \mathrm{C}\right)$; mobilna faza A: voda/fosforna kiselina $\left(\mathrm{H}_{3} \mathrm{PO}_{4}\right)(99,97: 0,03), \mathrm{pH}=2,75 \mathrm{i}$ mobilna faza B: $10 \% \mathrm{~A}$ u acetonitrilu. Gradijentni protok je bio: 0 min $90 \%$ A, $10 \%$ B; 5-15 min 75\% A, $25 \%$ B; 20 $\min 70 \% \mathrm{~A}, 30 \% \mathrm{~B} ; 25 \mathrm{~min} 50 \% \mathrm{~A}, 50 \% \mathrm{~B} ; 30 \mathrm{~min} 30 \% \mathrm{~A}$, $70 \%$ B i 35 min $90 \%$ A, 10\% B. Identifikacija komponenti izvršena je poređenjem ultraljubičastih (UV) spektara i retencionih vremena sa odgovarajućim standardima.

Ispitivanje antimikrobne aktivnosti etanolnih ekstrakata nevena i tradicionalnih masti na bazi nevena

Antimikrobna aktivnost etanolnih ekstrakata nevena i tradicionalnih masti na bazi nevena ispitana je agar-difuzionom metodom (16). Ispitivanje je izvršeno na šest standardnih laboratorijskih sojeva: Staphylococcus aureus ATCC 25923, Staphylococcus epidermidis ATCC 12228, Enterococcus faecalis ATCC 29212, Bacillus subtilis ATCC 6633, Pseudomonas aeruginosa ATCC 27853 i Candida albicans ATCC 10259 (Quick-stick, Microbiologics, USA).

Sojevi su kultivisani u triptikaza soja bujonu preko noći. Inokulum je napravljen od suspenzije prekonoćne kultu- re bakterija/gljivica i podešen na gustinu od 0,5 po Mekfarland (McFarland) standardu. Agar-difuzioni metod je izveden na Miler-Hinton (Mueller-Hinton) agaru (Torlak, Beograd) za bakterije i Saburo (Sabouraud) agaru (Torlak, Beograd) za gljivice. Aplikovano je po $50 \mu \mathrm{L}$ masti na bazi nevena (prethodno otopljene na temperaturi od $40^{\circ} \mathrm{C}$ ), odnosno po $50 \mu \mathrm{L}$ etanolnih ekstrakata. Kao negativna kontrola su korišćeni $70 \%$ etanol i svinjska mast. Nakon 24 časa kultivacije u aerobnim uslovima na $35^{\circ} \mathrm{C}$ očitane su zone inhibicije rasta u $\mathrm{mm}$. Svaki eksperiment je ponovljen četiri puta.

\section{Rezultati}

\section{Makroskopska i mikroskopska analiza}

Makroskopskom analizom cvasti nevena uočeno je da su jezičasti cvetovi žuti ili narandžastožuti, sa 3 zupca na vrhu, dok su cevasti cvetovi oko $5 \mathrm{~mm}$ dugi i sa žutom ili narandžastocrvenom krunicom, nagorkog ukusa i slabog mirisa. Analizirani uzorci nevena iz privatnih bašti u Kikindi, Mokrinu i Vrnjačkoj Banji odgovarali su zahtevima navedenim u monografiji Ph. Eur. 7.0 za Calendulae flos (15).

Mikroskopskom analizom cvasti nevena u prašku utvrđene su sledeće karakteristike: mehaničke višećelijske dlake, žlezdane dlake sa dvoćelijskom glavicom, bodljikava okruglasta polenova zrna i kristali kalcijum-oksalata, koji su odgovarali zahtevima navedenim u monografiji Ph.Eur 7.0 za Calendulae flos (15) (Tabela 1).

\section{Sadržaj flavonoida u cvasti nevena, Calendulae flos}

Određivan je sadržaj flavonoida u cvasti nevena sa različitih lokaliteta (Tabela 2). Sadržaj ukupnih flavonoida u svim ispitivanim uzorcima iznosio je 1,45-2,76\%, što je odgovaralo zahtevima navedenim u monografiji $P h$. Eur. 7.0, koja propisuje minimalnu koncentraciju ukupnih flavonoida u cvasti nevena $(0,4 \%)(15)$. Koncentracija flavonoida se nije značajno razlikovala u uzorcima jezičastih cvetova gajenog nevena i u komercijalnom uzorku. Iz dobijenih rezultata ustanovljeno je da su izdvojeni jezičasti cvetovi sakupljeni u septembru $(2,76 \pm 0,01 \%)$ sadržali veću koncentraciju flavonoida od celih cvasti $(1,68 \pm$ $0,00 \%)$. U jezičastim cvetovima tokom septembra sadržaj flavonoida je bio veći nego u novembru, dok se u celim cvetovima koncentracija nije značajno menjala. Veća koncentracija flavonoida tokom septembra verovatno je u korelaciji sa klimatskim uslovima u tom periodu. 
Tabela 1. Mikroskopska analiza cvasti nevena u prašku sa različitih lokaliteta

\begin{tabular}{llll}
\hline Lokalitet & Kikinda & Mokrin & Vrnjačka Banja \\
\hline Boja praška & Narandžast & Žut & Tamnonarandžast \\
& Kapi ulja narandžaste boje & Kapi ulja žutonarandžaste boje & Kapi ulja tamno narandžaste boje \\
& Višećelijske mehaničke dlake & Višećelijske mehaničke dlake & Višećelijske mehaničke dlake \\
& Žlezdane dlake & Žlezdane dlake & Žlezdane dlake \\
Karakteristični & Okruglasta polenova zrna & Okruglasta polenova zrna & Okruglasta polenova zrna \\
& Delovi parenhima & Delovi parenhima & Delovi parenhima \\
& & Sprovodni elementi sa kalcijum-ok- & Sprovodni elementi sa kalci- \\
& & salatom & jum-oksalatom \\
\hline
\end{tabular}

Tabela 2. Sadržaj flavonoida (\%) u cvasti nevena sa različitih lokaliteta i u komercijalnom uzorku

\begin{tabular}{|c|c|c|c|c|c|}
\hline \multirow[b]{3}{*}{ Jezičasti cvetovi } & \multicolumn{2}{|c|}{ Kikinda } & Mokrin & rnjačka Banja & Komercijalni uzorak \\
\hline & \multirow{2}{*}{$\frac{\text { Septembar }}{2,76 \pm 0,01}$} & \multirow{2}{*}{$\begin{array}{l}\text { Novembar } \\
1,45 \pm 0,01\end{array}$} & \multicolumn{2}{|c|}{ Septembar } & - \\
\hline & & & $2,00 \pm 0,06$ & $2,16 \pm 0,01$ & $2,28 \pm 0,01$ \\
\hline Cele cvasti & $1,68 \pm 0,00$ & $1,46 \pm 0,00$ & - & - & - \\
\hline
\end{tabular}

\section{Analiza flavonoida pomoću HPLC metode}

Analizom etanolnih ekstrakata cvasti ili jezičastih cvetova HPLC metodom identifikovano je prisustvo flavonoida 3-O-heterozida izoramnetina i kvercetina. U etilacetatnim ekstraktima su, nakon kisele hidrolize heterozida, dokazani flavonoidni aglikoni kvercetin $(\operatorname{tr}=26,7 \mathrm{~min})$ i izoramnetin ( $\operatorname{tr}=29,4 \mathrm{~min})$ (Grafikon 1). Kvercetin i izoramnetin su identifikovani u uzorcima jezičastih cve- tova nevena sa svih lokaliteta. Hromatogram etanolnog ekstrakta na $370 \mathrm{~nm}$ HPLC metodom prikazan je na Grafikonu 2.

Ispitivanje antimikrobne aktivnosti etanolnih ekstrakata $i$ tradicionalnih masti na bazi nevena

Etanolni ekstrakti jezičastih cvetova i celih cvasti, kao i tradicionalne masti na bazi jezičastih cvetova nevena

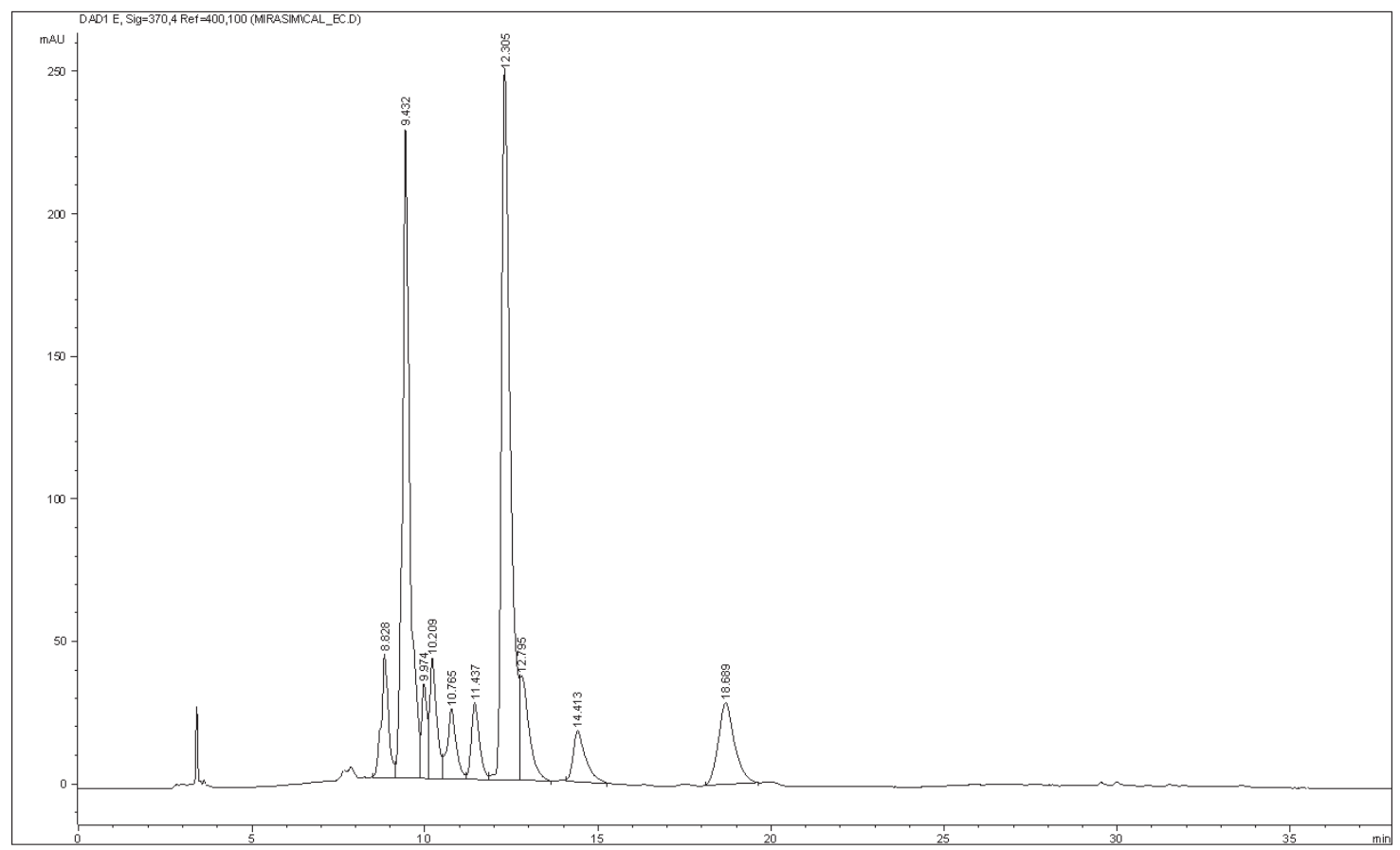

Grafikon 1. HPLC hromatogram etanolnog ekstrakta jezičastih cvetova nevena (1:20) na $370 \mathrm{~nm}$ (Kikinda, septembar 2015). Pikovi sa retencionim vremenima od 8,9 do 19,3 min odgovaraju 3-O-heterozidima izoramnetina i kvercetina. 


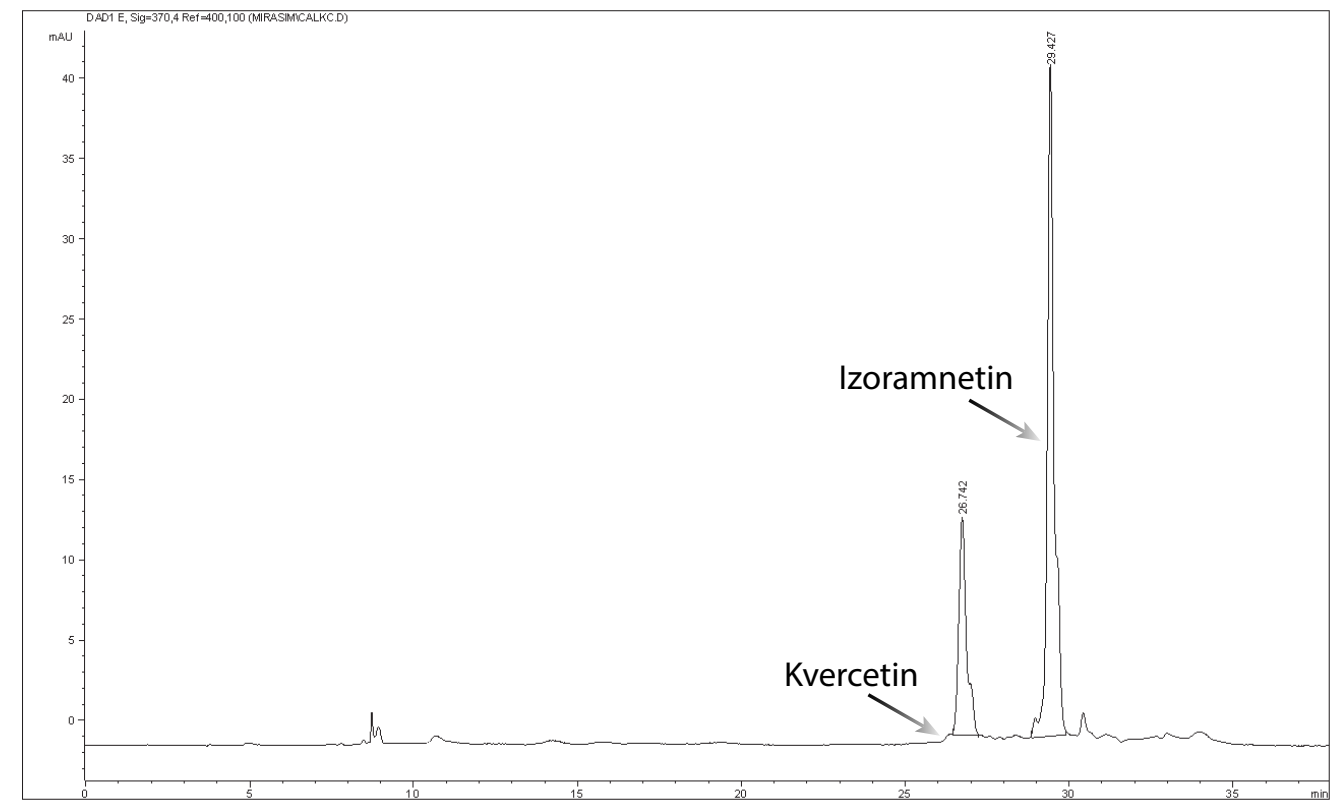

Grafikon 2. HPLC hromatogram etilacetatnog ekstrakta jezičastih cvetova nevena nakon hidrolize heterozida na $370 \mathrm{~nm}$ (Kikinda, septembar 2015).

pokazali su antimikrobno delovanje na ispitivane sojeve (Tabela 3.). Etanolni ekstrakti smanjuju rast bakterija $S$. aureus, S. epidermidis, E. faecalis, P. aeruginosa i B. subtilis. Tradicionalna mast na bazi jezičastih cvetova (3\%) inhibirala je rast mikroorganizama $S$. aureus, S. epidermidis, E. faecalis, P. aeruginosa i B. subtilis. Mast sa većim sadržajem jezičastih cvetova (9\%) pokazala je, međutim, slabije antimikrobno delovanje i inhibirala rast bakterija S. epidermidis, E. faecalis i P. aeruginosa, dok je na B. subtilis ispoljila bakteriostatski efekat. Mast celih cvasti nevena je pokazala najslabiju aktivnost, inhibirala je samo rast soja S. epidermidis. Sve ispitivane masti i etanolni ekstrakti nisu inhibirali rast C.albicans.

\section{Diskusija}

Sadržaj flavonoida u cvasti nevena, Calendulae flos

Ispitivani uzorci su sadržali znatno višu koncentraciju flavonoida $(1,45-2,76 \%)$ od ranijih istraživanja, gde je sadržaj flavonoida u uzorcima cvasti nevena iz osam evropskih država i Brazila iznosio od 0,21 do 0,68\%. (17-18). U prethodnim ispitivanjima, ekstrakti lista i cvasti nevena pokazali su relativno nisku antioksidantnu aktivnost. Ekstrakti različite polarnosti lista ili cvasti nevena (konc. 250-1000 $\mu \mathrm{g} / \mathrm{mL}$ ) inhibirali su 2,4-11,8\% 2,2-difeni-1-pikrilhidrazil (DPPH) radikala i pokazali 7,4-42,2\% ukupne redukcione sposobnosti u testu sposobnosti redukcije

Tabela 3. Antimikrobna aktivnost etanolnih ekstrakata i masti na bazi jezičastih cvetova ili celih cvasti nevena izražena kao zona inhibicije (mm)

\begin{tabular}{|c|c|c|c|c|c|c|c|}
\hline \multirow[b]{4}{*}{ Mikroorganizam } & \multicolumn{7}{|c|}{ Zona inhibicije (mm) } \\
\hline & \multicolumn{2}{|c|}{ Etanolni ekstrakt (DER 1:20) } & \multirow{2}{*}{$\begin{array}{c}\text { Mast } 1 \\
3 \%{ }^{c}\end{array}$} & \multirow{2}{*}{$\begin{array}{c}\text { Mast } 2 \\
9 \% c\end{array}$} & \multirow{2}{*}{$\begin{array}{c}\text { Mast } 3 \\
16 \%^{c}\end{array}$} & \multicolumn{2}{|c|}{ Kontrola } \\
\hline & & & & & & Etanol & Mast \\
\hline & jezičasti $^{\mathrm{a}}$ & cele cvasti & \multicolumn{2}{|c|}{ jezičasti } & cele cvasti & & \\
\hline S. aureus & $22,0 \pm 1,4^{\mathrm{b}}$ & $23,5 \pm 0,7^{b}$ & $13,5 \pm 1,0$ & 0 & 0 & 0 & 0 \\
\hline S. epidermidis & $22,5 \pm 0,7^{\mathrm{b}}$ & $20,5 \pm 0,7^{\mathrm{b}}$ & $11,0 \pm 0,8$ & $12,0 \pm 1,2$ & $14,3 \pm 2,4$ & $15,5 \pm 0,7^{\mathrm{b}}$ & 0 \\
\hline E. faecalis & $20,5 \pm 0,7^{b}$ & $20,0 \pm 0,0^{\mathrm{b}}$ & $13,0 \pm 1,8$ & $9,25 \pm 0,5$ & 0 & 0 & 0 \\
\hline P. aeruginosa & $20,5 \pm 0,7^{\mathrm{b}}$ & $19,5 \pm 0,7^{\mathrm{b}}$ & $11,0 \pm 1,2$ & $11,5 \pm 1,3$ & 0 & 0 & 0 \\
\hline B. subtilis & $22,5 \pm 0,7^{b}$ & $23,5 \pm 2,1^{b}$ & $10,8 \pm 1,5$ & $9,5 \pm 1,0^{\mathrm{b}}$ & 0 & 0 & 0 \\
\hline C. albicans & 0 & 0 & 0 & 0 & 0 & $17,0 \pm 1,41$ & 0 \\
\hline
\end{tabular}

a jezičasti cvetovi C. officinalis; ${ }^{\mathrm{b}}$ zone smanjenog rasta; ${ }^{\mathrm{c}}$ sadržaj jezičastih cvetova ili celih cvasti u masti 
feri jona (engl. Ferric reducing ability of plasma, FRAP) Najbolja aktivnost uočena je kod ekstrakata sa najvećim sadržajem polifenola i flavonoida i verovatno postoji korelacija između sadržaja ukupnih polifenola i flavonoida i antioksidantnog delovanja (13).

\section{Analiza flavonoida pomoću HPLC metode}

Dobijeni rezultati su u skladu sa prethodnim ispitivanjima, gde su utvrđeni heterozidi izoramnetina i kvercetina: rutin, izoramnetin-3-O-rutinozid, 3-O-glukozid izoramnetina, izokvercitrin, kao i kafena, hlorogenska i galna kiselina $(7,19)$.

Ispitivanje antimikrobne aktivnosti etanolnih ekstrakata $i$ tradicionalnih masti na bazi nevena

Etanolni ekstrakti jezičastih cvetova i celih cvasti, kao i tradicionalna mast na bazi jezičastih cvetova nevena (3\%) pokazali su isti spektar antimikrobnog delovanja, dok je mast sa većim sadržajem jezičastih cvetova (9\%) pokazala slabije antimikrobno delovanje. Razlog za ovakvu aktivnost je verovatno vreme uzorkovanja cvasti nevena, jer je mast sa $9 \%$ jezičastih cvetova izrađena od svežeg uzorka iz novembra, a tradicionalna mast sa $3 \%$ cvetova od svežeg uzorka iz septembra. Mast celih cvasti nevena pokazala je najslabiju antimikrobnu aktivnost, verovatno zbog korelacije sa sadržajem flavonoida u celim cvastima nevena.

Prethodno objavljeni radovi su pokazali da etanolni estrakti cvasti nevena inhibiraju rast mikroorganizama $S$. aureus $(19 \mathrm{~mm})$, B. subtilis $(10 \mathrm{~mm})$, B. cereus $(10 \mathrm{~mm})$, E. faecalis $(15 \mathrm{~mm})$, P. aeruginosa $(10 \mathrm{~mm})$, Escherichia coli $(14 \mathrm{~mm})$, Klebsiella pneumoniae $(14 \mathrm{~mm})$, K. aerogenes $(12$ $\mathrm{mm}$ ) i gljivica Candida albicans $(9 \mathrm{~mm})$, Aspergillus flavus $(7 \mathrm{~mm})$ i $A$. niger $(9 \mathrm{~mm})(11)$. $U$ istraživanju etanolnih ekstrakata celih cvasti nevena Gojala (Goyal) i Matura (Mathur) uočena je aktivnost na sojeve E. coli $(29,4 \mathrm{~mm})$, P. aeruginosa $(19,2 \mathrm{~mm})$, C. albicans $(25,6 \mathrm{~mm})$ i C. pa-

\section{Literatura}

1. Gazim ZC, Rezende CM, Fraga SR, Svidzinski TI, Cortez DA. Antifungal activity of the essential oil from Calendula officinalis L. (Asteraceae) growing in Brazil. Braz J Microby. 2008 ; 39:61-63.

2. Gajic M. Rod Calendula L. In: Josifović M, editor. Flora SR Srbije VII. Beograd: Srpska akademija nauka i umetnosti; 1975. pp. 170-172.

3. Pintea A, Bele C, Andrei S, Socaciu C. HPLC analysis of carotenoids in four varieties of Calendula officinalis L. flowers. Acta Biologica Szegediensis. 2003; 47:37-40.

4. Della Loggia R, Tubaro A, Sosa S, Becker H, Saar S, Isaac O. The role of triterpenoids in the topical antiinflammatory activity of Calendula officinalis flowers. Planta Medica. 1994; 60:516-520.

5. Vidal-Ollivier E, Elias R, Faure F, Babadjamian A, Crespin, F, Balansard G, et al. Flavonal Glycosides from Calendula officinalis flowers. Planta Medica. $1989 ; 55: 73-74$.

6. Bilia AR, Salvini D, Mazzi G, Vincieri FF. Characterization of calendula flower, milk-thistle fruit, and passion flower tinctures by HPLC-DAD and HPLC-MS. Chromatographia. 2001; 53:210-215. rapsilosis $(26,4 \mathrm{~mm})(20)$. Varijacije u antimikrobnoj aktivnosti etanolnih ekstrakata cvasti nevena u prethodno objavljenim radovima verovatno su posledica različitih ekoloških uslova staništa na kojima su biljke rasle, vremena prikupljanja biljnog materijala, postupaka ekstrakcije, kao i različitih izvora mikroorganizama. Prethodnim istraživanjima Efstratiu (Efstratiou) i sar. pokazano je da je metanol bolji rastvarač za ekstrakciju polifenola. Potvrđeno je i da metanolni i etanolni ekstrakti pokazuju antimikrobnu aktivnost, kao i da metanolni ekstrakt cvasti nevena pokazuje veću antimikrobnu aktivnost od etanolnog ekstrakta crasti nevena (11). Antimikrobno delovanje se verovatno zasniva na aktivnosti flavonoida. Flavonoidna frakcija izolovana iz cvasti nevena inhibirala je rast sojeva S. aureus, Sarcina lutea, E. coli, K. pneumoniae i C. monosa (21). Iako je u prethodnim istraživanjima uočena antifungalna aktivnost na različite vrste roda Candida, $\mathrm{u}$ našem ispitivanju etanolni ekstrakti i mast na bazi nevena nisu pokazali delovanje na gljivicu C. albicans. S obzirom na to da antimikrobna aktivnost tradicionalnih masti na bazi nevena nije prethodno ispitivana, rezultati dobijeni u ovom radu su važni i za dalje usmeravanje u istraživanju ovakvih tradicionalnih preparata.

\section{Zaključak}

Na osnovu makroskopske i mikroskopske analize i određivanja sadržaja flavonoida utvrđeno je da cvast gajenog nevena odgovara zahtevima Ph. Eur. 7.0. Ispitivanje sadržaja flavonoida u jezičastim cvetovima ili celoj cvasti nevena prikupljenih tokom septembra pokazalo je da jezičasti cvetovi sadrže više flavonoida od celih cvasti. U novembarskom uzorku, međutim, nije postojala značajna razlika u sadržaju flavonoida. Etanolni ekstrakti i tradicionalne masti na bazi jezičastih cvetova pokazale su antimikrobnu aktivnost na ispitivane sojeve, što potvrđuje dugogodišnju upotrebu nevena u vidu tradicionalnih i farmaceutskih proizvoda.

7. Butnariu M, Coradini CZ. Evaluation of Biologically Active Compounds from Calendula officinalis flowers using spectrophotometry. Chem Cent J. $2012 ; 6: 35$

8. Tucakov J. Lečenje biljem, 5th ed. Beograd: Rad; 1990. p.514.

9. Wichtl M. Herbal drugs and phytopharmaceuticals. 3rd ed. Stuttgart: Medpharm Scientific Publisher; 1994. p.446.

10. Arora D, Rani A, Sharma A. A review on phytochemistry and ethnopharmacological aspects of genus Calendula. Pharmacogn Rev. 2013; 7(14):179-187.

11. Efstratiou E, Hussain AI, Nigam PS, Moore JE, Ayub MA, Rao JR. Antimicrobial activity of Calendula officinalis petal extracts against fungi, as well as Gram-negative and Gram-positive clinical pathogens. Complement Ther Clin Pract. 2012;18(3):173-176.

12. Leporatti ML, Ivancheva S. Preliminary comparative analysis of medicinal plants used in the traditional medicine of Bulgaria and Italy. J Ethnopharmacol. 2003; 87(2-3): 123-142. 
13. Ercetin $\mathrm{T}$, Senol FS, Orhan IE, Toker G. Comparative assessment of antioxidant and cholinesterase inhibitory properties of the marigold extracts from Calendula arvensis L. and Calendula officinalis L. Ind Crops Prod. 2012; 36:203-208.

14. European Medicines Agency. Community Herbal Monograph on Calendula officinalis L., flos. London: Doc. Ref. EMEA/HMPC/179281/2007Corr.1.; 2008.

15. Council of Europe. European Pharmacopoeia. 7th ed. Strasbourg: Council of Europe; 2010.

16. Clinical and Laboratory Standards Institute (CLSI). Performance Standards for Antimicrobial Susceptibility Testing. Seventeenth Informational Supplement. CLSI Document M100-S17. Wayne, PA: Clinical and Laboratory Standards Institute; 2007.
17. Raal A, Kirsipuu K. Total flavonoid content in varieties of Calendula officinalis L. originating from different countries and cultivated in Estonia. Nat Prod Res. 2011; 25(6):658-662.

18. Honório IC, Bonfim FP, Montoya SG, Casali VW, Leite JP, Cecon PR. Growth, development and content of flavonoids in calendula (Calendula officinalis L.). Acta Sci Agron. 2016; 38(1):69-75.

19. Matysik G, Wójciak-Kosior M, Paduch R. The influence of Calendulae officinalis flos extracts on cell cultures, and the chromatographic analysis of extracts. J Pharm Biomed Anal. 2005; 38(2):285-92.

20. Goyal M, Mathur R. Antimicrobial effects of Calendula officinalis against human pathogenic microorganisms. J Herbal Med Tox. 2011; 5(1):97-101.

21. (21) Ríos JL, Recio MC, Villar A. Antimicrobial activity of selected plants employed in the Spanish Mediterranean area. J Ethnopharmacol. 1987; 21:139-152. 